Review

\title{
Extracellular vesicles and pancreatitis: mechanisms, status and perspectives
}

\author{
Yu-Chen Jia ${ }^{1,2^{*}}$, Yi-Xuan Ding ${ }^{1,2^{*}}$, Wen-Tong Mei ${ }^{1,2}$, Yu-Ting Wang ${ }^{3}$, Zhi Zheng ${ }^{1,2}$, Yuan-Xu Qu1,2, Kuo \\ Liang $^{1,2}$, Jia Li1 ${ }^{1,2}$, Feng $\mathrm{Cao}^{1,2}$ and Fei $\mathrm{Li}^{1,2}$ \\ 1. Department of General Surgery, Xuanwu Hospital, Capital Medical University, Beijing, China. \\ 2. Clinical Center for Acute Pancreatitis, Capital Medical University, Beijing, China. \\ 3. Capital Medical University, Beijing, China. \\ *These authors contributed equally to this work. \\ $\square$ Corresponding authors: Professor Fei Li, E-mail: feili36@ccmu.edu.cn. Professor Feng Cao, E-mail: caofeng1221@163.com.
}

( ) The author(s). This is an open access article distributed under the terms of the Creative Commons Attribution License (https://creativecommons.org/licenses/by/4.0/). See http://ivyspring.com/terms for full terms and conditions.

Received: 2020.10.22; Accepted: 2020.12.23; Published: 2021.01.11

\begin{abstract}
Comprehensive reviews and large population-based cohort studies have played an important role in the diagnosis and treatment of pancreatitis and its sequelae. The incidence and mortality of pancreatitis have been reduced significantly due to substantial advancements in the pathophysiological mechanisms and clinically effective treatments. The study of extracellular vesicles (EVs) has the potential to identify cell-to-cell communication in diseases such as pancreatitis. Exosomes are a subset of EVs with an average diameter of 50 150 nm. Their diverse and unique constituents include nucleic acids, proteins, and lipids, which can be transferred to trigger phenotypic changes of recipient cells. In recent years, many reports have indicated the role of EVs in pancreatitis, including acute pancreatitis, chronic pancreatitis and autoimmune pancreatitis, suggesting their potential influence on the development and progression of pancreatitis. Plasma exosomes of acute pancreatitis can effectively reach the alveolar cavity and activate alveolar macrophages to cause acute lung injury. Furthermore, upregulated exosomal miRNAs can be used as biomarkers for acute pancreatitis. Here, we summarized the current understanding of EVs in pancreatitis with an emphasis on their biological roles and their potential use as diagnostic biomarkers and therapeutic agents for this disease.
\end{abstract}

Key words: pancreatitis, extracellular vesicles, exosomes, biomarkers

\section{Introduction}

Pancreatitis refers to an inflammatory disorder of the pancreas, in which pancreatic enzymes damage pancreatic tissue, leading to acinar cell death, as well as local and systemic inflammation [1]. Previous studies have shown that acute pancreatitis, recurrent acute pancreatitis, and chronic pancreatitis represent a continuum of disease progression. Per 100,000 people in the general population, the global incidence of acute pancreatitis is 33.74 cases per year and that of chronic pancreatitis is 9.62 cases per year [2]. Similar to acute pancreatitis, chronic pancreatitis is most prevalent in middle-aged and older patients [3,4]. However, the incidence of chronic pancreatitis was higher among men than women, although there was no significant difference between sexes for acute pancreatitis. The global transition rate data indicated that the transition from the first episode of acute pancreatitis to recurrent acute pancreatitis occurs in approximately $21 \%$ of cases and that from recurrent acute pancreatitis to chronic pancreatitis occurs in approximately $36 \%$ of cases [5]. The global mortality rates of acute pancreatitis and chronic pancreatitis were 1.60 and 0.09 per 100,000 persons per year, respectively [2]. Recently, clinical and experimental data have shed light on the pathophysiology of pancreatitis, indicating that premature intrapancreatic activation of digestive proteases is critical in the pathogenesis of pancreatitis [6]. Furthermore, the progression and severity of pancreatitis may be influenced by dysregulated autophagy, which 
promotes the inflammatory response in the pancreas, leading to local and systemic inflammatory responses and multiorgan failure [7]. Unfortunately, the sequelae and mortality of pancreatitis remain substantial. Concerted efforts by not only surgeons but also researchers should strive to reduce the incidence of pancreatitis and effectively improve the treatment of its sequelae [8-10].

EVs are cell-derived membranous structures that are present in biological fluids and are involved in physiological and pathological processes of inflammatory disease or cancer [11-15]. EVs were initially regarded as membrane debris with no biological function [16]. However, in 2007, exosomes were shown to transfer mRNAs and microRNAs to recipient cells, remained functional and changed the behavior of target cells [17]. EVs exert their effects on fundamental biological processes by directly merging with the recipient cell plasma membrane and delivering their contents, including transcription factors, oncogenes, microRNAs and mRNAs, into recipient cells [18-20]. In this manner, EVs participate in the pathophysiological process of disease, for example, stem cell therapy [21], tissue repair [22], immune surveillance [23], and tumor progression and metastasis [24,25]. In addition, several studies have reported the potential applications of EVs in the diagnosis and treatment of disease based on their own characteristics.

Here, we report a comprehensive overview of the relationship between EVs and pancreatitis, with a special focus on their roles in pathogenesis and their potential clinical application as diagnostic biomarkers and therapeutic targets in pancreatitis. We also discuss the advantages and limitations among current studies and the need for further research. Finally, we discuss the prospects and applications of EVs in pancreatitis.

\section{EVs: clinical applications}

EVs are regarded as a mechanism for intercellular communication, transferring proteins, lipids and genetic material between cells [26]. Based on the current knowledge of their biogenesis by transmission electron microscopy, NanoSight analysis and other biochemical means, EVs can be broadly divided into two main categories: exosomes and microvesicles (MVs) [27,28]. In addition, the pathophysiological roles of EVs are applied in the diagnosis of diseases including cancer and inflammatory diseases, especially in their potential treatments for therapeutic intervention $[29,30]$.

Table 1. The role of EVs in pancreatitis

\begin{tabular}{|c|c|c|c|c|c|}
\hline Pancreatitis & Category & Source of EVs & Related molecules & Effects & References \\
\hline \multirow[t]{6}{*}{$\mathrm{AP}$} & \multirow[t]{3}{*}{ Pathogenesis } & Mice plasma & $\begin{array}{l}\text { IL-1 } \beta, \text { IL-6, CCL-2, MRC1, } \\
\text { CD36 }\end{array}$ & $\begin{array}{l}\text { The increased plasma exosomes of acute pancreatitis effectively reach the } \\
\text { alveolar cavity and activate alveolar macrophages in AP. }\end{array}$ & {$[76]$} \\
\hline & & $\begin{array}{l}\text { Mice plasma, Mice } \\
\text { PAAF }\end{array}$ & $\begin{array}{l}\text { miR-155, miR-122, miR-21, } \\
\text { TERRA, IL-1 } \beta, \text { CCL2, CXCL1 }\end{array}$ & $\begin{array}{l}\text { The liver could be the source of plasma exosomes that activate the } \\
\text { inflammatory response in the lung, rather than the pancreas, during AP. }\end{array}$ & [77] \\
\hline & & Mice plasma & NLRP3,IL-1 $\beta$ & $\begin{array}{l}\text { Plasma exosomes triggered NOD-like receptor protein } 3 \text { (NLRP3)-dependent } \\
\text { pyroptosis in alveolar macrophages, which induced AP-associated ALI. }\end{array}$ & [83] \\
\hline & Diagnosis & AR42J cell & miRNAs & $\begin{array}{l}\text { Upregulated extracellular vesicle miRNAs in } \\
\text { TRAF6-TAB2-TAK1-NIK/IKK-NF } \kappa \text { B pathway may be used as biomarkers for } \\
\text { AP. }\end{array}$ & [89] \\
\hline & Treatment & MSCs & Klotho, IL-6, TNF-a,Bax, Bcl-2 & $\begin{array}{l}\text { Exosomes derived from mesenchymal stem cells that overexpress Klotho } \\
\text { attenuated the severity of pancreatic inflammation in caerulein-stimulated } \\
\text { AR42J cells. }\end{array}$ & [101] \\
\hline & & Mice plasma & NLRP3,IL-1 $\beta$ & $\begin{array}{l}\text { Exosome-mediated NLRP3 pathway is a potential therapeutic target for the } \\
\text { treatment of ALI during AP. }\end{array}$ & {$[83]$} \\
\hline \multirow[t]{8}{*}{$\mathrm{CP}$} & Pathogenesis & PSC & CCN2,miR-21 & $\begin{array}{l}\text { CCN2 up-regulation in PSC is associated with increased expression of miR-21 } \\
\text { which, in turn, is able to stimulate CCN2 expression further via a positive } \\
\text { feedback loop. Additionally miR-21 and CCN2 were identified in } \\
\text { PSC-derived exosomes which effected their delivery to other PSC. }\end{array}$ & [116] \\
\hline & Diagnosis & Human plasma & $\begin{array}{l}\text { miR-10b, miR-20a, miR-21, } \\
\text { miR-30c, miR-106b, miR-181a, } \\
\text { miR-let7a }\end{array}$ & Clear differentiation between PDAC and CP. & [117] \\
\hline & & $\begin{array}{l}\text { Human Pancreatic } \\
\text { juice }\end{array}$ & miR-21, miR-155 & Clear differentiation between PDAC and CP. & [118] \\
\hline & & Human serum & miR-125b, miR-148a & Clear differentiation between PDAC and CP. & [119] \\
\hline & & Human serum & miR-10b,miR-23b-3p & Clear differentiation between PC and CP. & {$[120,121]$} \\
\hline & & Human serum & DNA & $\begin{array}{l}\text { Circulating exosomal KRAS and TP53 mutations can be used to distinguish } \\
\text { healthy subjects from those with PDAC and PC. }\end{array}$ & [122] \\
\hline & & $\begin{array}{l}\text { Human bile, } \\
\text { Human serum }\end{array}$ & EVs' concentrations & Discriminate malignant from nonmalignant CBD stenoses. & [123] \\
\hline & Treatment & PSC & CCN2, miR-21 & $\begin{array}{l}\text { Inhibiting exosome secretion and the expression of CNN2 and miR-21 may } \\
\text { reduce the inflammatory response caused by PSC activation in the } \\
\text { development of CP. }\end{array}$ & [116] \\
\hline AIP & Pathogenesis & Human serum & miR-21 & Diagnostic marker to distinguish AIP from healthy people. & [126] \\
\hline
\end{tabular}




\section{Diagnostic potential of EVs}

The biomedical applications of EVs take advantage of their contents in the diagnosis and treatment of disease. The characteristic properties of EVs involve delivering functional cargos to diseased cells or EVs derived from diseased cells can affect normal cells; furthermore, EVs remain ill-defined in terms of their biological characteristics and functions [31]. EVs contain a large number of extracellular and intracellular molecular components, which can be used as minimally invasive liquid biopsies for comprehensive, multiparameter disease diagnosis. EVs are diagnostic biomarkers for diseases include stroke [32], Alzheimer's disease [33], cardiovascular diseases [34] and cancer [35]. Exosomal miRNAs are the most widely used diagnostic biomarkers, especially in cancer [36]. Specific exosomal miRNAs may be diagnostic or prognostic markers in cancer. Furthermore, highly expressed oncogenic and tumorsuppressor miRNAs in exosomes may provide high diagnostic value due to their differential expression between cancer cells and normal cells, especially in the early diagnosis of diseases [37]. Similarly, exosomal proteins also have diagnostic potential for diseases. Several studies have reported the utility of glypican-1 (GPC1)-positive exosomes in the diagnosis of pancreatic cancer [38-40]. GPC1 is specifically enriched in pancreatic patient serum-derived exosomes, distinguishing chronic patients and healthy people from patients with early- or late-stage pancreatic cancer. Thus, the multicomponent and combinatorial nature of exosomal proteins and miRNAs could potentially enhance the specificity and sensitivity of cancer diagnosis and prognostic evaluation. Therefore, EVs can be used as biomarkers for disease diagnosis because disease-generating exosomes can reflect disease-specific changes.

\section{Therapeutic potential of EVs}

According to the characteristics of EVs that can contain DNA, RNA and proteins, exosomes by themselves or as vehicles for drug delivery have therapeutic potential in diseases [41-43]. Exosomes, as natural endogenous drugs, have obvious advantages in delivering functional cargo to cells. Compared with liposomes, exosomes are widely distributed in body fluids with low immunogenicity and minimal immune clearance. Furthermore, their phospholipid bilayer effectively protects the loaded drugs, making them stable in the blood [44]. Several studies reported that exosomes from mesenchymal stem cells (MSCs) or dendritic cells inhibit disease progression by transporting siRNAs [45], miRNAs [46,47], and chemotherapy drugs [48-50]. In addition, ligand- modified exosomes may be used to enhance their targeting ability to specific cell types [51,52]. For example, previous studies reported that the integrinspecific recognition peptide RGD was applied for exosome membrane modification to enhance the exosome targeting capability [53]. Tian et al. reported that exosomes derived from immature dendritic cells deliver doxorubicin to human breast cancer cells, inhibiting tumor progression without obvious toxicity [54]. Together, these clinical and experimental data contribute to the development of exosomes as therapeutic vesicles.

\section{EVs and AP}

\section{EVs in the pathogenesis of AP}

Previous studies have reported that the pathogenesis of acute pancreatitis includes calcium signaling [55], premature trypsinogen activation [56], autophagy [57], endoplasmic reticulum stress, the unfolded protein response [58], intraductal fluid stasis [59], immune system [60], genetic mutations [61], unsaturated fatty acids [62] and mesenteric lymph [63], which mainly lead to trypsinogen activation and injury of acinar cells. The most common and earliest organ dysfunction of AP-associated complications is acute lung injury (ALI), accounting for approximately $10-25 \%$ of the incidence and $60 \%$ of the mortality [63-65]. Underlying mechanisms of AP-associated ALI are complex and poorly understood, although recent perspectives have indicated that pancreatic phospholipase A2, proinflammatory cytokines, neutrophil sequestration and bacterial translocation are involved in the mechanisms of AP and ALI [66-68].

In recent years, the role of exosomes has been gradually clarified in the pathogenesis and treatment of inflammatory diseases, especially in AP [69-75]. Bonjoch et al. illustrated that the increased plasma exosomes of acute pancreatitis effectively reach the alveolar cavity and activate alveolar macrophages in an experimental rat model of taurocholate-induced acute pancreatitis [76]. Moreover, in vitro experiments showed that plasma exosomes activate alveolar macrophages from the M2 phenotype to a proinflammatory M1 phenotype, concurrent with significantly increased expression of the M1 marker cytokines IL-1 $\beta$ and IL- 6 and the chemokine CCL-2 and decreased expression of the M2 markers MRC1 and CD36. In addition, mass spectrometry-driven proteomic analysis of plasma exosomes indicated that the 33 significantly differentially expressed proteins were mainly derived from liver and immune cells; however, the expression of protein derived from the pancreas was downregulated. Thus, proteomic 
analysis suggested that the most likely origin of plasma exosomes could be the liver instead of the pancreas. Tracking analysis and histological analysis revealed that the liver retains almost $75 \%$ of exosomes from pancreatitis-associated ascitic fluid (PAAF). Furthermore, exosomes filtered by the liver changed not only in number but also in protein content. These results indicated that the liver could be generating and releasing new exosomes during $\mathrm{AP}$, which could reach the alveoli and activate alveolar macrophages to a proinflammatory phenotype (Figure 1).

Jiménez-Alesanco et al. performed further experiments to show that the liver could be the source of plasma exosomes that activate the inflammatory response in the lung, rather than the pancreas, during AP [77]. These researchers provided evidence that plasma exosomes and PAAF exosomes differ in microRNA (miRNA) content, protein, distribution and physiological effects. Exosomal miRNA analysis revealed that plasma exosomes contained high expression of miR-155 and low expression of miR-122 and miR-21; however, the expression of these miRNAs in PAAF exosomes was similar to that in the control group. Previous studies have shown that miR-155 has a proinflammatory role that can promote M1 polarization of macrophages [78]. In contrast, miR-122, which is mainly produced by the liver, plays an anti-inflammatory role $[79,80]$. Therefore, the results suggested that proinflammatory miR-155 expression was significantly upregulated, concurrent with a significant decrease in anti-inflammatory miR-21 and miR-122 expression in plasma exosomes, which could play a proinflammatory response by activating macrophages and promoting the release of inflammatory cytokines. Moreover, proteomic analysis revealed that the proteins of plasma exosomes were mainly from the liver; however, only two specific pancreatic proteins were detected. PAAF exosomes contained high levels of pancreatic enzymes, which confirmed their pancreatic origin. However, histones and ribosomal proteins were more enriched in PAAF exosomes but not in plasma exosomes. Furthermore, histone proteins produce telomeric repeat-containing RNA (TERRA) by regulating noncoding RNA transcripts, which are carried by exosomes from damaged cells to induce an inflammatory response [81,82]. They also evaluated the different effects of plasma exosomes and PAAF exosomes on alveolar macrophages. The results showed that plasma exosomes significantly increased the expression of the inflammatory cytokine IL-1 $\beta$ and chemokines CCL2 and CXCL1 in alveolar macrophages; however, the increase in inflammatory factors was not statistically significant in PAAF exosomes compared with that in the control group. The results indicated that these highly expressed miRNAs and proteins could be targeted for designed therapeutic drugs for the treatment of AP (Figure 2).

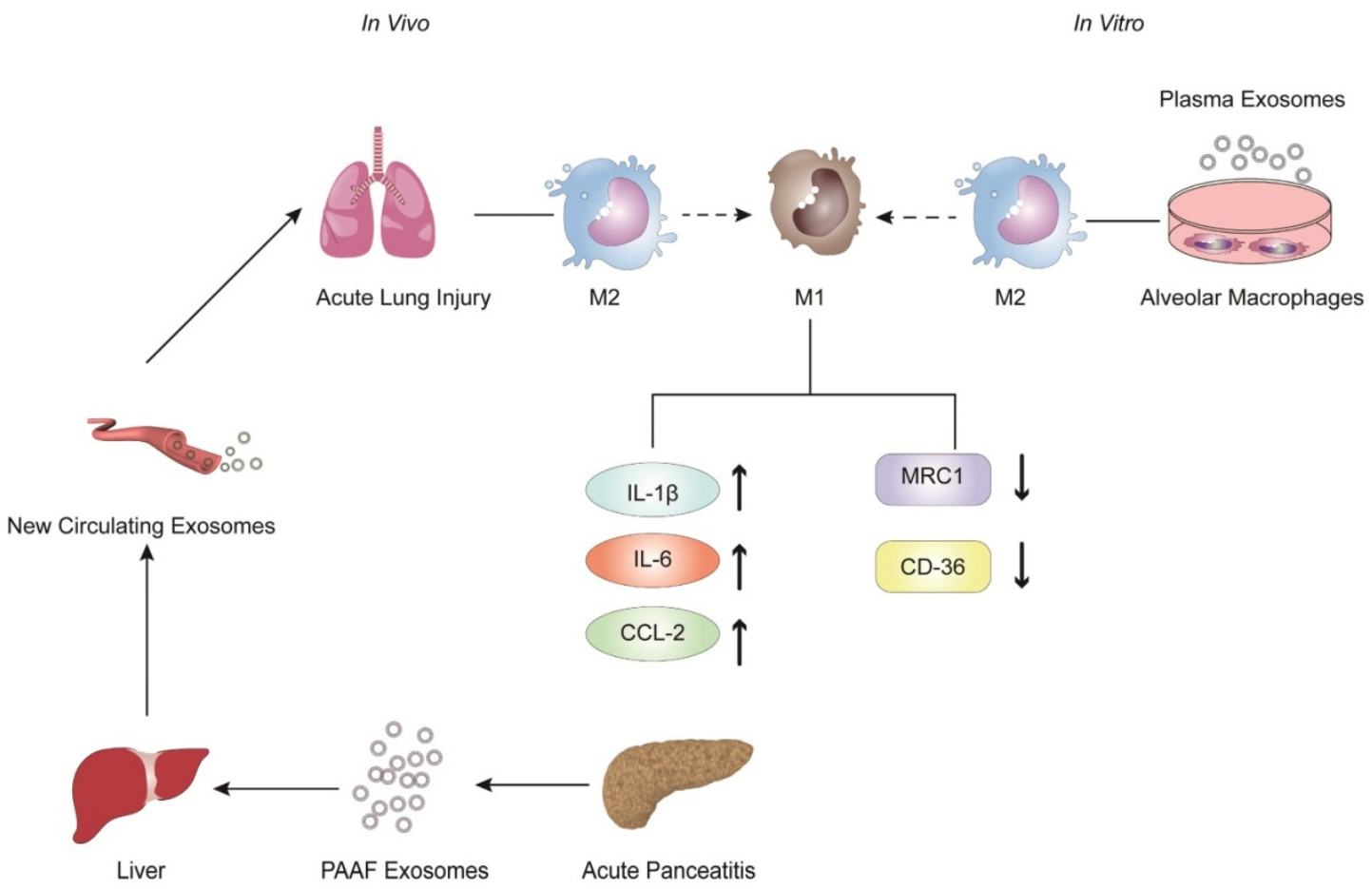

Figure 1. The role of extracellular vesicles in the mechanism of AP-related alveolar macrophage activation. The figure shows that in vitro experiments (left) revealed that part of the PAAF exosomes released from the pancreas during AP entered the liver directly through the portal system, and most of them were retained in liver tissue. During AP, the formation of new circulating exosomes from the liver reached the alveoli and activated the alveolar macrophages from the M2 phenotype to the pro-inflammatory M1 phenotype, leading to significantly increased expression of cytokines IL-1, IL-6 and chemokine CCL2, while the expression of MRC1 and CD36 was decreased. In vivo experiments (right) showed that plasma exosomes from AP promoted the activation of alveolar macrophages from the M2 phenotype to the pro-inflammatory M1 phenotype, and resulted in significantly increased expression of the inflammatory cytokines IL-1 and the chemokine CCL2 in alveolar macrophages. 


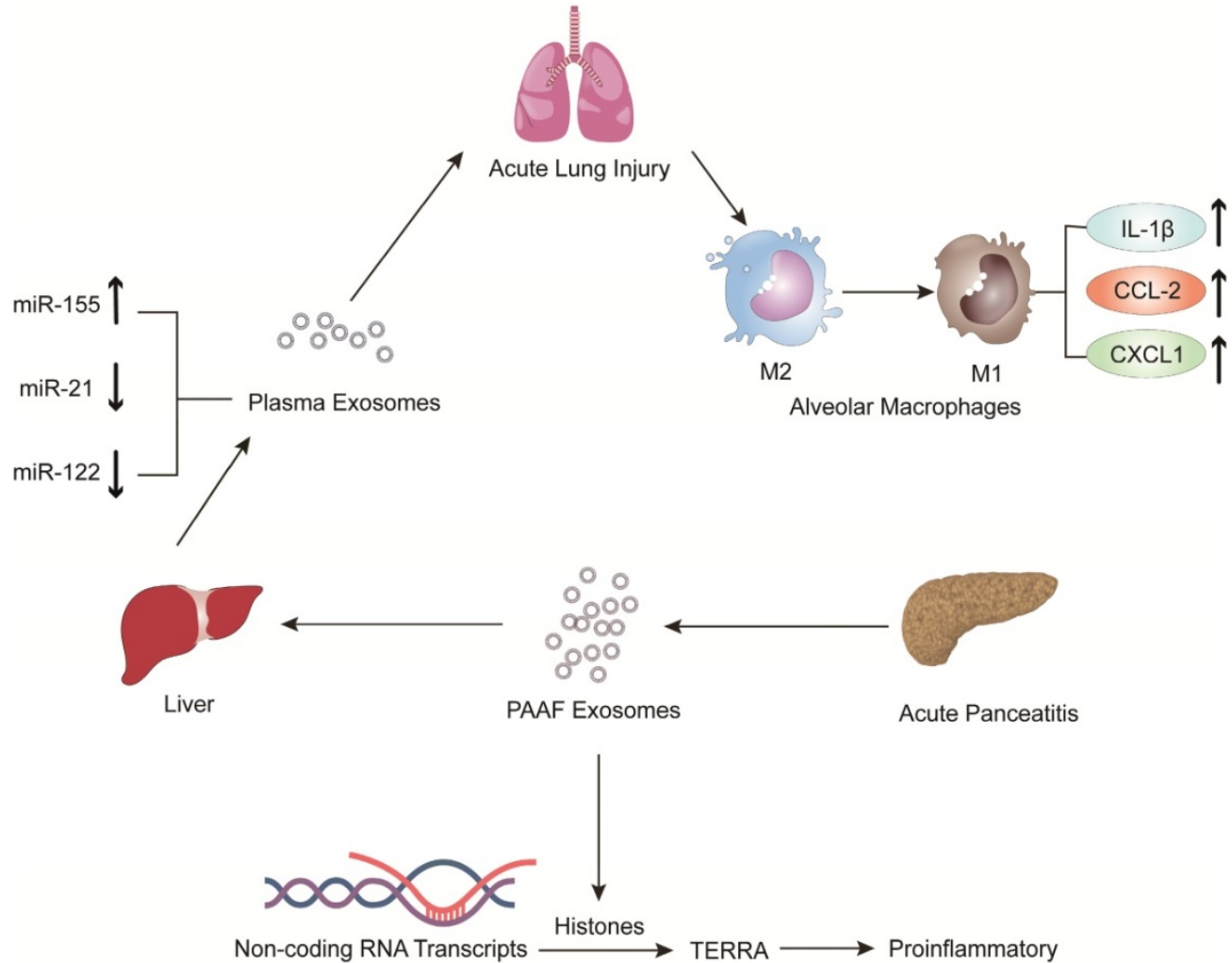

Figure 2. The expression of pro-inflammatory miR-155 in plasma exosomes produced during AP was significantly increased, while the expressions of anti-inflammatory miR-122 and miR-21 were decreased. The arrival of plasma exosomes to the alveoli and by activating alveolar macrophages leads to increased expression of the inflammatory cytokines IL-1 and the chemokines CCL2 and CXCL1, thus exacerbating AP-related lung injury. In addition, PAAF exosomes produced during AP contain more histones, which induce inflammation by regulating the transcription of non-coding RNA to produce TERRA.

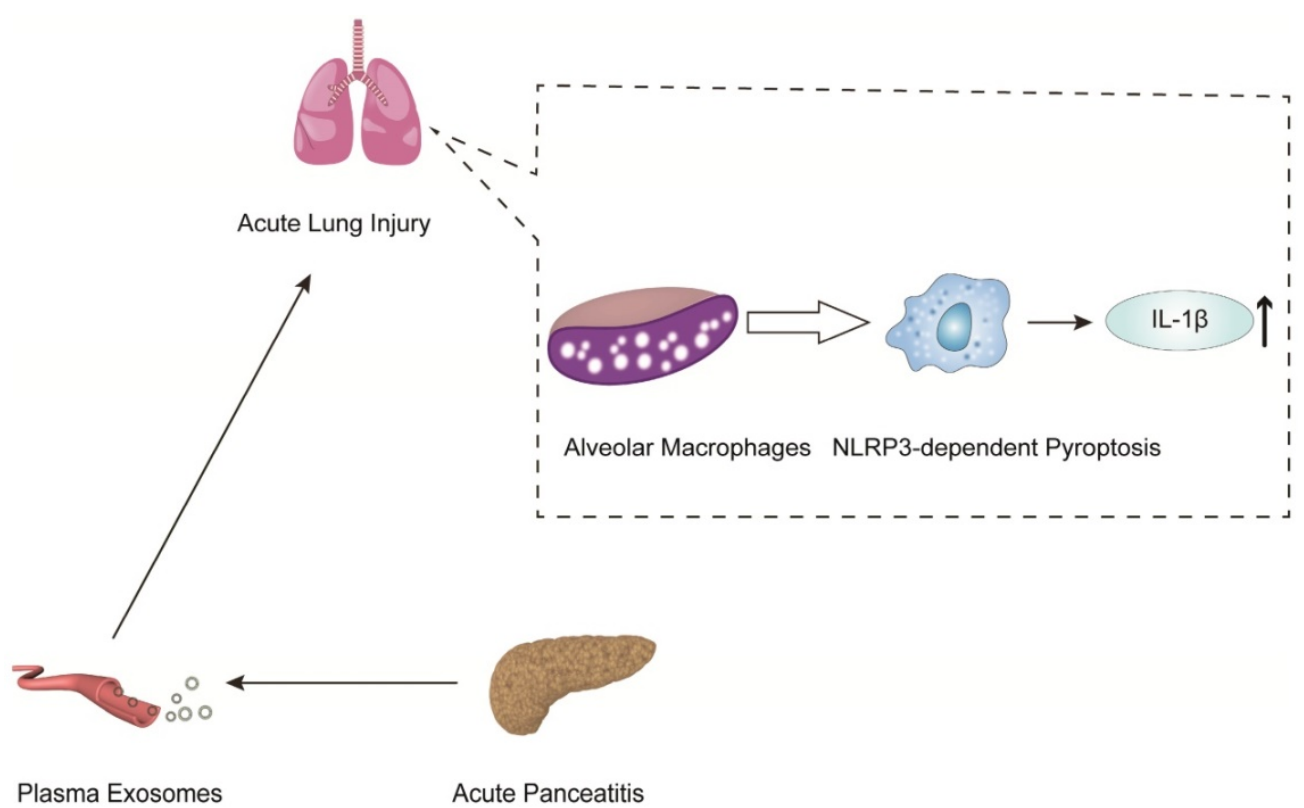

Figure 3. AP-generated plasma exosomes activate NLRP3 inflammasomes in alveolar macrophages and induce NLRP3-dependent pyroptosis, leading to apoptosis in alveolar macrophages and increased expression of the inflammatory cytokine IL-1.

In another mechanistic study of pancreatitisassociated $\mathrm{ALI}, \mathrm{Wu}$ et al. indicated that plasma exosomes triggered NOD-like receptor protein 3 (NLRP3)-dependent pyroptosis in alveolar macrophages, which induced AP-associated ALI [83] (Figure 3). The present work revealed that plasma exosomes stimulated alveolar macrophages to activate the NLRP3 inflammasome, released IL-1 $\beta$ and induced pyroptosis, suggesting that the plasma exosome-mediated NLRP3 pathway is a potential therapeutic target for the treatment of ALI during AP (Figure 3). 


\section{EVs in the diagnosis of AP}

There are many studies on exosomal miRNAs as a diagnostic marker of inflammatory disease, including alcoholic hepatitis [84], inflammatory liver diseases [85], diabetes mellitus [86], liver disease [87], and Parkinson's disease [88]. However, there are only a few studies on exosomal miRNAs as diagnostic biomarkers for AP [89]. Zhao et al. indicated that 115 differentially expressed exosomal miRNAs of the pancreatic acinar cell line AR42J were identified by a miRNA microarray. Among the differentially expressed miRNAs, 30 were upregulated and 85 were downregulated. Therefore, these 30 upregulated miRNAs may be used as biomarkers for AP. However, the results of this study are only derived from in vitro experiments and have not been verified by in vivo experiments and human samples. It is not yet known whether there are any types of interference, such as differential expression and exosome rupture. Furthermore, target genes of the identified miRNAs were predicted using TargetScan and analyzed by KEGG pathway analysis. The pathways included cell adhesion molecules (CAMs), glycerophospholipid metabolism, the Wnt signaling pathway, the MAPK signaling pathway and the Hedgehog signaling pathway. After further analysis and verification, the target genes regulated macrophage and $N F \kappa B$ activation through the TRAF6-TAB2-TAK1-NIK/IKK-NFאB pathway, which

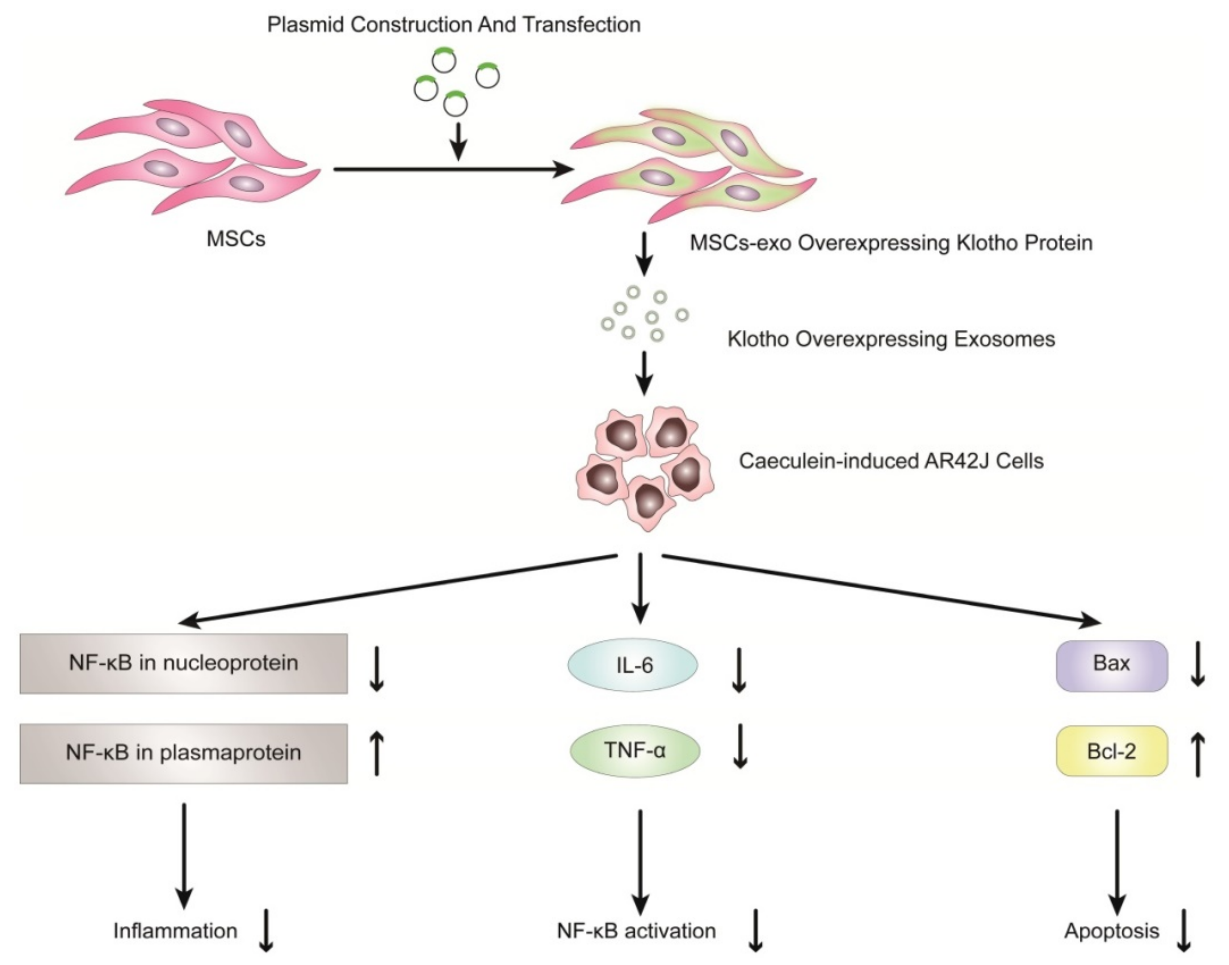

Figure 4. Overexpression of Klotho protein in exosomes from genetically engineered mesenchymal stem cells can reduce the inflammatory response of pancreatic acinar cells (AR42J cells) in the model of acute pancreatitis induced by caerulein. is one of the MAPK signaling pathways. Therefore, the present study provides new ways to alleviate pancreatitis-associated macrophage activation and potential diagnostic exosomal biomarkers for AP.

\section{EVs in the treatment of AP}

Previous studies have shown that exosomes derived from mesenchymal stem cells (MSCs) can be used to reduce inflammatory responses and treat inflammatory diseases [90-100]. Therefore, MSCderived exosomes have potential clinical value in the treatment of inflammatory diseases, especially pancreatitis. Wang et al. reported that exosomes derived from mesenchymal stem cells that overexpress Klotho attenuated the severity of pancreatic inflammation in caerulein-stimulated AR42J cells [101]. Klotho, which is expressed in pancreases, is essential for digestive enzyme secretion from pancreatic acinar cells [102]. In this study, exosomes derived from MSCs that overexpressed Klotho (MSCs-exo Klotho) decreased the expression of IL- 6 and TNF-a compared to that of the control group. Furthermore, the expression of Bax and NF-kB in nucleoproteins was significantly downregulated in the MSC-exo Klotho group, concurrent with a significant increase in the expression of Bcl-2 and NF-kB in plasma proteins. In conclusion, these results showed that MSC-exo Klotho alleviated inflammation and apoptosis in AP and that Klotho could be a potential targeted therapy for clinical treatment in $\mathrm{AP}$ (Figure 4).

\section{EVs and CP}

\section{EVs in the pathogenesis of CP}

Chronic pancreatitis is a chronic inflammatory disease that is characterized by fibrosis and inflammation of the pancreas, with genetic, environmental, and other risk factors [103-107]. The pathophysiological processes of $\mathrm{CP}$ mainly involve acinar cell injury [108,109], inflammation [110] and fibrosis by activated pancreatic stellate cells [111]. Studies have shown that activated pancreatic stellate cells (PSCs) are considered a promoter of pancreatic fibrosis, which is a crucial hallmark of $\mathrm{CP}$ [112-115]. Activated PSCs are 
the main producers of connective tissue growth factor (CCN2), which plays an important role in driving fibrogenic pathways to stimulate extracellular matrix collagen production. Charrier et al. found that the expression of CCN2 and miR-21 is upregulated in PSCs [116]. CCN2 not only drives collagen expression but also stimulates the expression of miR-21, which can itself increase CCN2 expression. Thus, upregulated CCN2 and miR-21 are components of a positive feedback loop that may be a mechanism for enhanced collagen production in CP. Additionally; the study indicated that the exosomes derived from activated PSCs contain CCN2 and miR-21, which can be shuttled to activate normal PSCs. Therefore, inhibiting exosome secretion and the expression of CNN2 and miR-21 can reduce the inflammatory response caused by PSC activation in the development of $\mathrm{CP}$ (Figure 5).

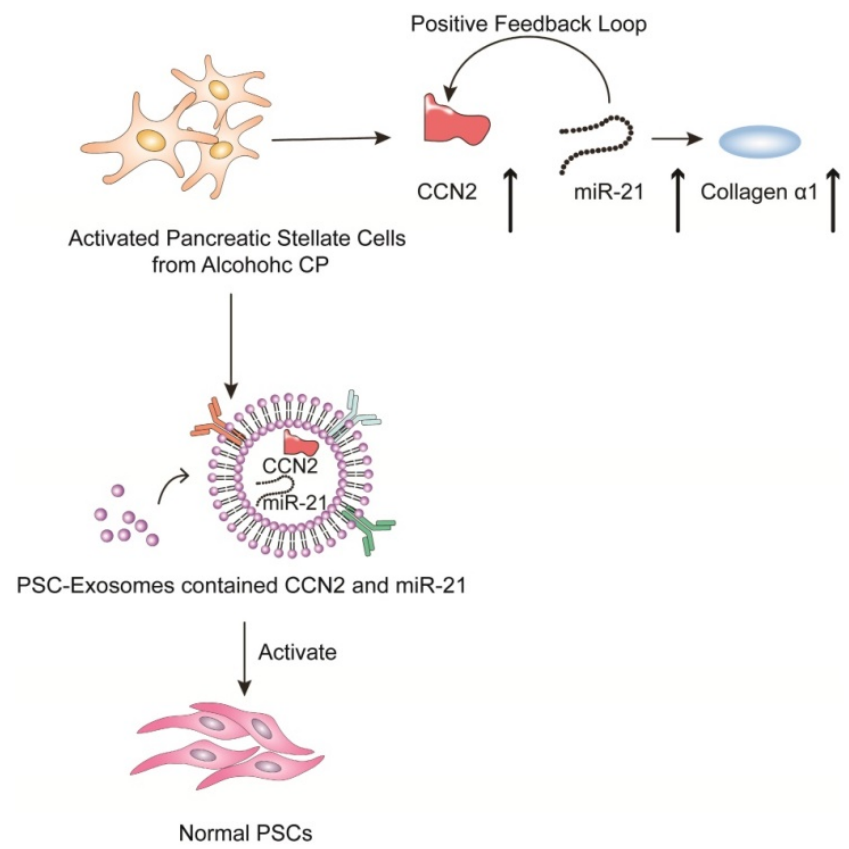

Figure 5. Role of extracellular vesicles in CP - associated pancreatic fibrosis. The figure shows that in activated PSC in alcoholic chronic pancreatitis, up-regulated $\mathrm{CCN} 2$ and miR-21 constitute a positive feedback pathway that promotes collagen $\alpha 1$ production. In addition, exosomes produced by activated PSCs contained CCN2 and miR-21, and these exosomes could activate more PSCs and produce more exosomes and collagen $\alpha 1$.

\section{EVs in the diagnosis of CP}

In the diagnosis of chronic pancreatitis, effective diagnostic biomarkers are still lacking.

At present, no study has indicated that exosomes can be used as diagnostic biomarkers to distinguish chronic pancreatitis from normal conditions. Pancreatic ductal adenocarcinoma (PDAC) is sometimes difficult to distinguish from chronic pancreatitis in the early clinical diagnosis. Furthermore, CP may be misdiagnosed as PDAC, leading to unnecessary pancreatic resection. Therefore, accurate early diagnosis and clear differentiation between PDAC and CP are crucial for patients [104,106].

In addition, several studies have shown that exosomal miRNAs can distinguish patients with chronic pancreatitis from those with PDAC. Lai et al. [117] found that high expression of exosomal miR-10b, miR-20a, miR-21, miR-30c, miR-106b and miR-181a and low expression of exosomal miR-let7a can effectively differentiate patients with PDAC from those with $\mathrm{CP}$. Moreover, after resection, the high expression of exosomal miR-10b, miR-20a, miR-21, miR-30c, and miR-106b decreased to normal values. Nakamura et al. [118] reported that they used exosomal miRNAs from pancreatic juice to distinguish patients with PDAC from those with CP. Quantitative real-time reverse transcription polymerase chain reaction (qRT-PCR) showed that the expression levels of exosomal miR-21 and miR-155 were significantly higher in the PDAC patients than in the $\mathrm{CP}$ patients. However, there were no significant differences observed in the expression levels of free miR-21 and free miR-155 in PDAC and CP patients. Furthermore, the AUC values of exosomal miR-21 and miR-155 levels were significantly higher than those for the serum CA19-9 levels. Therefore, exosomal miRNAs may be useful and stable biomarkers for distinguishing patients with chronic pancreatitis from those with PDAC.

Reese et al. used qRT-PCR to show that the expression of miR-200b and miR-200c was significantly downregulated in serum exosomes of PDAC patients compared to healthy controls (HCs) and patients with CP. Moreover, the expression of exosomal miR-125b was significantly upregulated in patients with $\mathrm{CP}$ compared to those with $\mathrm{HC}$, and the expression of exosomal miR-148a was significantly upregulated in patients with $\mathrm{CP}$ compared to PDAC patients [119]. Therefore, exosomal miR-125b and miR-148a can be used as specific diagnostic biomarkers to distinguish $\mathrm{CP}$ patients from patients with HC and PDAC, respectively. Similarly, other studies have shown that exosomal miR-10b and miR23b-3p can also distinguish CP from PDAC [120,121].

Furthermore, several studies have shown that exosomal DNA can distinguish patients with chronic pancreatitis from those with PDAC. Yang et al. [122] indicated that circulating exosomal double stranded genomic DNA derived from PDAC patients enabled the detection of prevalent KRAS and TP53 mutations. Digital PCR of exosomal DNA identified KRAS mutations in 29 of 48 (39.6\%) cases and TP53 mutations in 2 of $48(4.2 \%)$ cases in PDAC patients. Moreover, they found that 3 of $7(42.8 \%)$ IPMN 
patients harbored the KRAS mutation, and one of these patients also coharbored the TP53 mutation. For $\mathrm{CP}$ patients, the KRAS mutation was found in 5 of 9 $(55.6 \%)$ cases; however, none had the TP53 mutation. In addition, 5 of $12(41.7 \%)$ patients with other diseases, such as autoimmune pancreatitis, common bile duct cancer, pancreatic cystadenoma, and pancreatic neuroendocrine tumor, harbored the KRAS mutation, and only 1 had the TP53 mutation. In healthy subjects, the KRAS mutation was observed in 3 of $114(2.6 \%)$ cases, and none had the TP53 mutation. Therefore, this study demonstrates that circulating exosomal KRAS and TP53 mutations can be used to distinguish healthy subjects from those with PDAC, $\mathrm{PC}$ and other diseases.

Several studies have applied exosomal miRNAs and DNA as diagnostic biomarkers of disease; however, whether the concentrations and diameter of EVs could discriminate malignant and benign disease has not been determined. Severino et al. [123] used the concentrations of EVs to discriminate malignant from nonmalignant CBD stenoses. They collected EVs derived from bile and blood samples and assessed them by nanoparticle tracking analyses (NTA). In bile samples, the concentration of EVs ranged between $1.78 \times 10^{12}$ and $1.31 \times 10^{16}$ nanoparticles/L, with an overall median value of $6.66 \times 10^{14}$ nanoparticles/L. In the PDAC group vs the biliary stones group, the median concentration of EVs was $2.41 \times 10^{15}$ vs $1.60 \times 10^{14}$ nanoparticles/L. Furthermore, a threshold of $9.46 \times 10^{14}$ nanoparticles/L in bile samples distinguished patients with PDAC from those with biliary stones. In the PDAC group vs the $\mathrm{CP}$ group, the median concentration of EVs was $4.00 \times 10^{15}$ vs $1.26 \times 10^{14}$ nanoparticles/L. The threshold of $9.46 \times 10^{14}$ nanoparticles/L discriminated PDAC from CP with $100 \%$ accuracy. In serum samples, the concentration of EVs was significantly lower than that in bile samples, with an overall median of $2.67 \times 10^{13}$ nanoparticles/L. The median concentration of EVs in the PDAC group vs the biliary stone group was $3.55 \times 10^{14}$ vs $1.74 \times 10^{13}$ nanoparticles/L. In the PDAC group vs the $\mathrm{CP}$ group, the median concentration of EVs was $4.64 \times 10^{13}$ vs $7.58 \times 10^{12}$ nanoparticles/L. In addition, the average diameter of EVs in the PDAC group was $277.8 \mathrm{~nm}$; however, the average diameter of EVs in the CP group was $169.9 \mathrm{~nm}$. Furthermore, EVs derived from bile have larger sizes and contain more proteins in the malignant vs nonmalignant group. Thus, the concentrations and diameters of EVs could be used to discriminate malignant from benign disease with optimal accuracy.

\section{EVs and AIP}

Autoimmune pancreatitis (AIP) is a special form of $\mathrm{CP}$ that has a pivotal role in inducing fibroinflammatory disorders of the pancreas [124,125]. The diagnosis and treatment of AIP have not achieved satisfactory clinical effects. Nakamaru et al. reported that the expression of miR-21 was significantly upregulated in extracellular vesicles derived from the serum of patients with type 1 autoimmune pancreatitis [126]. This study included 27 patients with type 1 AIP, 23 patients with chronic pancreatitis and 23 healthy controls (HCs). Microarray analysis showed 165 differentially expressed miRNAs in patients with type 1 AIP. Furthermore, 132 miRNAs were upregulated and 33 were downregulated in type 1 AIP patients compared with HCs. Among these results, the expression levels of miR-659-3p, miR-27a-3p, miR-99a-5p, miR-21-5p, miR-205-5p, miR-100-5p, miR-29c-3p, and miR-126b-1-3p were significantly upregulated, concurrent with a significant decrease in miR-4252 and miR-5004-1-5p expression relative to that of the HCs. Quantitative evaluation of EV miRNA expression levels by RT-PCR showed that only the expression level of miR-21-5p was significantly higher in type 1 AIP patients than in HCs. Furthermore, the results of in situ hybridization (ISH) of resected specimens of type 1 AIP patients showed that the expression of miR-21 in pancreatic duct epithelium was similar between type 1 AIP patients and HCs. However, miR-21 was highly expressed in pancreatic acinar cells in type 1 AIP patients compared to HCs. Therefore, this study demonstrated that miR-21 in EVs derived from AIP patients' serum could be used as a diagnostic marker to distinguish AIP from healthy people.

\section{Shortcoming and perspectives}

The study of EVs has the potential to identify cellular and molecular communication and value in the diagnosis and treatment of diseases [26,31]. Due to their diverse and unique contents, such as nucleic acids, proteins, lipids, and metabolites, EVs not only can reflect their origin cells but can also be used as a diagnostic marker for disease. In addition, EVs protect their contents through their stable membrane structure and serve as an effective carrier for drug delivery in the therapeutics of cancer and inflammatory diseases [15,36,127].

In recent years, EV research has focused on the classification of EVs, isolation methods, and their functions in disease diagnosis, progression and therapy [30,128-130]. Despite the increase in different isolation methods of EVs, there are still no uniform and standardized methods available for the purification and isolation of EVs [131,132]. Therefore, it remains unclear whether different isolation methods of EVs may lead to different results [26]. 
Currently, there is a need to establish standardized methods of sample collection, storage, and application to minimize the influence of the complexity and heterogeneity of EVs [133]. In addition, the conventional isolation methods of exosomes in blood, such as ultracentrifugation, cannot completely remove lipoprotein, which is similar in size and density to EVs [134]. However, the volume and time of blood collection, handling, storage condition and application of anticoagulants all impact the isolation of EVs [135]. For the isolation of EVs from cultured cells, it is recommended to use serum-free medium or EV-free serum in cell culture medium [136]. For clinical blood sample collection, it is important to minimize the influence of the activation and release of platelet and red blood cell-derived EVs and the contamination of cell debris. A number of studies have shown that $-80^{\circ} \mathrm{C}$ and minimized freeze-thaw cycles are the optimum conditions for the storage of EVs based on size, composition, and functionality. An unfavorable temperature and increased freeze-thaw cycles can cause EV aggregation and lysis, leading to an increase in size, a reduction in counting and a loss of content. The current methods of EV isolation mainly include ultracentrifugation, size-exclusion chromatography, filtration, commercial reagents, microfluidics, asymmetric flow field-flow fractionation, and nanoflow cytometry [133]. Diverse methods have their advantages and disadvantages. Moreover, high-efficiency isolation of EVs is needed to eliminate protein contamination and increase purity for clinical application of EVs.

In the diagnosis of $\mathrm{AP}$, there are only a few studies on exosomal biomarkers for AP. Zhao et al. indicated that 30 exosomal miRNAs were upregulated in pancreatic acinar AR42J cells and could be used as biomarkers for AP. However, the results of this study are only derived from in vitro experiments and have not been verified by in vivo experiments and human samples [89]. Therefore, for an EV diagnostic biomarker of AP, large samples and multicenter clinical studies are needed. In the diagnosis of $\mathrm{CP}$, no literature has indicated that EVs can be used as diagnostic biomarkers to distinguish $\mathrm{CP}$ patients from healthy people. However, PDAC is sometimes difficult to distinguish from $\mathrm{CP}$ in the early clinical diagnosis, leading to unnecessary pancreatic resection $[104,106]$. Therefore, Lai et al. [117] found that high expression of exosomal miR-10b, miR-20a, miR-21, miR-30c, miR-106b and miR-181a can effectively differentiate patients with PDAC from those with $\mathrm{CP}$. After resection, the high expression of these miRNAs decreased to normal values. Moreover, Nakamura et al. [118] reported that the expression of exosomal miR-21 and miR-155 from pancreatic juice was significantly higher in PDAC patients than in CP patients. Compared with those of serum CA19-9 levels, the AUC values of exosomal miR-21 and miR-155 levels were significantly higher. Therefore, exosomal miRNAs may be useful and stable biomarkers for distinguishing patients with $\mathrm{CP}$ from those with PDAC. Furthermore, several studies have shown that exosomal DNA can also distinguish patients with $\mathrm{CP}$ from those with PDAC and healthy subjects. Yang et al. [122] indicated that exosomal DNA identified KRAS mutations in 29 of 48 (39.6\%) cases and TP53 mutations in 2 of $48(4.2 \%)$ cases in PDAC patients. For CP patients, the KRAS mutation was found in 5 of $9(55.6 \%)$ cases; however, none had the TP53 mutation. In healthy subjects, the KRAS mutation was observed in 3 of 114 (2.6\%) individuals, and none had the TP53 mutation. Therefore, the study indicates that circulating exosomal KRAS and TP53 mutations can be used to distinguish patients with $\mathrm{CP}$ from those with PDAC and healthy subjects.

In recent years, compared with exosomal miRNAs and DNA as diagnostic biomarkers of disease, the concentrations and diameters of EVs could discriminate PDAC and CP patients [123]. In bile samples, the median concentration of EVs was $4.00 \times 10^{15}$ vs $1.26 \times 10^{14}$ nanoparticles/L in the PDAC group vs the $\mathrm{CP}$ group. In serum samples, the median concentration of EVs was $4.64 \times 10^{13}$ vs $7.58 \times 10^{12}$ nanoparticles/L in the PDAC group vs the CP group. In addition, the average diameter of EVs in the PDAC group was $277.8 \mathrm{~nm}$; however, the average diameter of EVs in the CP group was $169.9 \mathrm{~nm}$. Thus, EVs derived from bile have larger sizes and contain more proteins in the PDAC vs CP group.

In the diagnosis of AIP, Nakamaru et al. reported that the expression of miR-21 was significantly upregulated in extracellular vesicles derived from serum from patients with type 1 autoimmune pancreatitis [126]. This study included 27 patients with type 1 AIP, 23 patients with chronic pancreatitis and 23 healthy controls (HCs). Microarray analysis and RT-PCR showed that the expression level of miR-21-5p was significantly higher in type 1 AIP patients than in HCs. Therefore, miR-21 of EVs derived from AIP patients' serum could be used as a diagnostic marker to distinguish AIP patients from healthy people. At present, there are no reports on potential therapeutic application of EVs in the treatment of AIP. However, it has been reported that EVs have potential therapeutic effect in other autoimmune diseases, such as type 1 diabetes mellitus, multiple sclerosis, systemic lupus erythematosus [134]. Research has been suggested that mesenchymal stem cells-derived exosomes might protect the pancreatic islets of patients with Type 1 
diabetes by immunomodulatory effect to slow disease progression [135]. Similarly, Multiple sclerosis (MS) is a $\mathrm{T}$ cell-mediated autoimmune disease, which underlying mechanisms are unclear. Kimura have showed that MS derived exosomal let-7i regulates MS pathogenesis by blocking the insulin like growth factor 1 receptor and transforming growth factor beta receptor 1 pathway [136]. Therefore, more studies are needed to further investigate the mechanism and treatment of EVs in AIP.

In the treatment of $\mathrm{AP}$, previous studies have shown that exosomes derived from MSCs can be used to reduce inflammatory responses and treat inflammatory diseases [90-100]. Therefore, Wang et al. reported that exosomes derived from mesenchymal stem cells that overexpress Klotho attenuated the severity of pancreatic inflammation in caeruleinstimulated AR42J cells [101]. In this study, exosomes derived from MSCs that overexpressed Klotho decreased the expression of IL-6 and TNF-a compared to the control group. In conclusion, these results showed that MSC-exo Klotho alleviated inflammation and apoptosis in AP and that Klotho could be a potential targeted therapy for clinical treatment in AP. However, EVs have not been applied for drug delivery in the treatment of AP. The application of drug-loaded EVs can effectively improve the targeting ability of drugs. In addition, compared with liposomes, EVs have an advantage in the application of drug delivery for targeted treatment.

\section{Conclusion}

In this review, we report a comprehensive overview of the relationship between EVs and pancreatitis, with a special focus on their roles in pathogenesis and their potential clinical applications as diagnostic biomarkers and therapeutic targets in pancreatitis. We have discussed EV isolation and application of clinical-grade EVs and the advantages and limitations of current studies, as well as the need for further research. EVs are regarded as a mechanism for intercellular communication, transferring proteins, lipids and genetic material in pancreatitis.

EVs are involved in the pathogenesis of pancreatitis and are used as diagnostic markers for pancreatitis and have clear potential as treatment targets in pancreatitis. However, there are still no uniform and standardized methods available for the purification and isolation of EVs. Therefore, it remains unclear whether different isolation methods of EVs may lead to different results. Currently, there is a need to establish standardized methods of sample collection, storage, and application to minimize the influence of the complexity and heterogeneity of EVs. EVs have not been applied drug delivery in the treatment of AP. Therefore, the clinical application of EVs in the diagnosis and treatment of pancreatitis is promising, and additional extensive research is required before clinical application.

\section{Abbreviations}

EVs: Extracellular vesicles; AP: Acute pancreatitis; CP: Chronic pancreatitis; AIP: Autoimmune pancreatitis; MVs: Exosomes and microvesicles; GPC1: Glypican-1; MSCs: Mesenchymal stem cells; ALI: Acute lung injury; PAAF: pancreatitis-associated ascitic fluid; miRNAs: microRNAs; TERRA: Telomeric repeat-containing RNA; NLRP3: NOD-like receptor protein 3; CAMs: Cell adhesion molecules; MSCs: Mesenchymal stem cells; MSCs-exo klotho: Exosomes derived from MSCs which overexpressed klotho; PSCs: Pancreatic stellate cells; CCN2: Connective tissue growth factor; PDAC: Pancreatic ductal adenocarcinoma; qRT-PCR: Quantitative real-time reverse transcription polymerase chain reaction; HC: Healthy control; IPMN: Intraductal papillary mucinous neoplasm; NTA: Nanoparticle tracking analyses; HCs: Healthy controls; ISH: In situ hybridization.

\section{Competing Interests}

The authors have declared that no competing interest exists.

\section{References}

1. Petrov MS, Yadav D. Global epidemiology and holistic prevention of pancreatitis. Nat Rev Gastroenterol Hepatol. 2019;16(3): 175-184.

2. Xiao AY, Tan ML, Wu LM, Asrani VM, Windsor JA, Yadav D, Petrov MS. Global incidence and mortality of pancreatic diseases: a systematic review, meta-analysis, and meta-regression of population-based cohort studies. Lancet Gastroenterol Hepatol. 2016; 1(1): 45-55.

3. Pendharkar SA, Mathew J, Petrov MS. Age- and sex-specific prevalence of diabetes associated with diseases of the exocrine pancreas: A populationbased study. Dig Liver Dis. 2017; 49(5): 540-544.

4. Pendharkar SA, Mathew J, Zhao J, Windsor JA, Exeter DJ, Petrov MS. Ethnic and geographic variations in the incidence of pancreatitis and postpancreatitis diabetes mellitus in New Zealand: a nationwide population-based study. N Z Med J. 2017; 130(1450): 55-68.

5. Sankaran SJ, Xiao AY, Wu LM, Windsor JA, Forsmark CE, Petrov MS. Frequency of progression from acute to chronic pancreatitis and risk factors: a meta-analysis. Gastroenterology. 2015;149(6):1490-1500.

6. Mayerle J, Sendler M, Hegyi E, Beyer G, Lerch MM, Sahin-Tóth M. Genetics, Cell Biology, and Pathophysiology of Pancreatitis. Gastroenterology. 2019; 156(7): 1951-1968.e1.

7. Gukovskaya AS, Gukovsky I, Algül H, Habtezion A. Autophagy, Inflammation, and Immune Dysfunction in the Pathogenesis of Pancreatitis. Gastroenterology. 2017; 153(5): 1212-1226.

8. Lee PJ, Papachristou GI. New insights into acute pancreatitis. Nat Rev Gastroenterol Hepatol. 2019; 16(8): 479-496.

9. Bakker OJ, Issa Y, van Santvoort HC, Besselink MG, Schepers NJ, Bruno MJ, et al. Treatment options for acute pancreatitis. Nature Review. 2014; 11(8): 462-9.

10. Hines OJ, Pandol SJ. Management of severe acute pancreatitis. BMJ. 2019; 367:16227.

11. Xu R, Rai A, Chen M, Suwakulsiri W, Greening DW, Simpson RJ. Extracellular vesicles in cancer implications for future improvements in cancer care. Nat Rev Clin Oncol. 2018; 15(10): 617-638.

12. Lindenbergh MFS, Stoorvogel W. Antigen Presentation by Extracellular Vesicles from Professional Antigen-Presenting Cells. Annu Rev Immunol. 2018; 36: 435-459.

13. Robbins PD, Morelli AE. Regulation of immune responses by extracellular vesicles. Nat Rev Immunol. 2014; 14(3): 195-208. 
14. Becker A, Thakur BK, Weiss JM, Kim HS, Peinado H, Lyden D. Extracellular Vesicles in Cancer: Cell-to-Cell Mediators of Metastasis. Cancer Cell. 2016; 30(6): 836-848.

15. Tran PHL, Xiang D, Tran TTD, Yin W, Zhang Y, Kong L, et al. Exosomes and Nanoengineering: A Match Made for Precision Therapeutics. Adv Mater Weinheim. 2020; 32(18): e1904040.

16. Johnstone RM, Adam M, Hammond JR, Orr L, Turbide C. Vesicle formation during reticulocyte maturation. Association of plasma membrane activities with released vesicles (exosomes). J Biol Chem. 1987; 262(19): 9412-20.

17. Valadi H, Ekström K, Bossios A, Sjöstrand M, Lee JJ, Lötvall JO. Exosomemediated transfer of mRNAs and microRNAs is a novel mechanism of genetic exchange between cells. Nat Cell Biol. 2007; 9(6): 654-9.

18. Barile L, Vassalli G. Exosomes: Therapy delivery tools and biomarkers of diseases. Pharmacol Ther. 2017; 174: 63-78

19. Syn NL, Wang L, Chow EK, Lim CT, Goh BC. Exosomes in Cancer Nanomedicine and Immunotherapy: Prospects and Challenges. Trends Biotechnol. 2017; 35(7): 665-676.

20. LeBleu VS, Kalluri R. Exosomes as a Multicomponent Biomarker Platform in Cancer. Trends Cancer. 2020; 6(9):767-774.

21. Chang YH, Wu KC, Harn HJ, Lin SZ, Ding DC. Exosomes and Stem Cells in Degenerative Disease Diagnosis and Therapy. Cell Transplant. 2018; 27(3): 349-363.

22. Qiu H, Liu S, Wu K, Zhao R, Cao L, Wang H. Prospective application of exosomes derived from adipose-derived stem cells in skin wound healing: A review. J Cosmet Dermatol. 2020; 19(3): 574-581.

23. Zhang HG, Zhuang X, Sun D, Liu Y, Xiang X, Grizzle WE. Exosomes and immune surveillance of neoplastic lesions: a review. Biotech Histochem. 2012; 87(3): 161-8.

24. Steinbichler TB, Dudás J, Riechelmann H, Skvortsova II. The role of exosomes in cancer metastasis. Semin Cancer Biol. 2017; 44: 170-181.

25. Milman N, Ginini L, Gil Z. Exosomes and their role in tumorigenesis and anticancer drug resistance. Drug Resist Updat. 2019; 45: 1-12.

26. Mathieu M, Martin-Jaular L, Lavieu G, Théry C. Specificities of secretion and uptake of exosomes and other extracellular vesicles for cell-to-cell communication. Nat Cell Biol. 2019; 21(1): 9-17.

27. Medeiros T, Myette RL, Almeida JR, Silva AA, Burger D. Extracellular Vesicles: Cell-Derived Biomarkers of Glomerular and Tubular Injury. Cell Physiol Biochem. 2020; 54(1): 88-109.

28. Liu C, Feng Q, Sun J. Lipid Nanovesicles by Microfluidics: Manipulation, Synthesis, and Drug Delivery. Adv Mater Weinheim. 2019; 31(45): e1804788.

29. EL Andaloussi S, Mäger I, Breakefield XO, Wood MJ. Extracellular vesicles: biology and emerging therapeutic opportunities. Nat Rev Drug Discov. 2020; 10: 3137.

30. van Niel G, D'Angelo G, Raposo G. Shedding light on the cell biology of extracellular vesicles. Nat Rev Mol Cell Biol. 2020; 9(4): 1044.

31. Kalluri R, LeBleu VS. The biology function and biomedical applications of exosomes. Science. 2020; 367(6478): eaau6977.

32. Otero-Ortega L, Laso-García F, Gómez-de Frutos M, Fuentes B, Diekhorst L, Díez-Tejedor E, et al. Role of Exosomes as a Treatment and Potential Biomarker for Stroke. Transl Stroke Res. 2019; 10(3): 241-249.

33. Hamlett ED, Goetzl EJ, Ledreux A, Vasilevko V, Boger HA, LaRosa A, et al. Neuronal exosomes reveal Alzheimer's disease biomarkers in Down syndrome. Alzheimers Dement. 2017; 13(5): 541-549.

34. Jansen F, Li Q. Exosomes as Diagnostic Biomarkers in Cardiovascular Diseases. Adv Exp Med Biol. 2017; 998: 61-70.

35. Skotland T, Ekroos K, Kauhanen D, Simolin H, Seierstad T, Berge V, et al. Molecular lipid species in urinary exosomes as potential prostate cancer biomarkers. Eur. J. Cancer. 2017; 70: 122-132.

36. Mori MA, Ludwig RG, Garcia-Martin R, Brandão BB, Kahn CR. Extracellular miRNAs: From Biomarkers to Mediators of Physiology and Disease. Cell Metab. 2019; 30(4): 656-673

37. Salehi M, Sharifi M. Exosomal miRNAs as novel cancer biomarkers: Challenges and opportunities. J Cell Physiol. 2018; 233(9): 6370-6380.

38. Melo SA, Luecke LB, Kahlert C, Fernandez AF, Gammon ST, Kaye J, et al. Glypican-1 identifies cancer exosomes and detects early pancreatic cancer. Nature. 2015; 523(7559): 177-82.

39. Lai X, Wang M, McElyea SD, Sherman S, House M, Korc M. A microRNA signature in circulating exosomes is superior to exosomal glypican-1 levels for diagnosing pancreatic cancer. Cancer Lett. 2017; 393: 86-93.

40. Lu H, Niu F, Liu F, Gao J, Sun Y, Zhao X, et al. Elevated glypican-1 expression is associated with an unfavorable prognosis in pancreatic ductal adenocarcinoma. Cancer Med. 2017; 6(6): 1181-1191.

41. Kourembanas S. Exosomes: vehicles of intercellular signaling, biomarkers, and vectors of cell therapy. Annu Rev Physiol. 2015; 77: 13-27.

42. Sun D, Zhuang X, Zhang S, Deng ZB, Grizzle W, Miller D, et al. Exosomes are endogenous nanoparticles that can deliver biological information between cells. Adv Drug Deliv Rev. 2013; 65(3): 342-7.

43. Lai RC, Yeo RW, Tan KH, Lim SK. Exosomes for drug delivery-a novel application for the mesenchymal stem cell. Biotechnol Adv. 2013; 31(5): 543-51.

44. Stremersch S, Vandenbroucke RE, Van Wonterghem E, Hendrix A, De Smedt SC, Raemdonck K. Comparing exosome-like vesicles with liposomes for the functional cellular delivery of small RNAs. J Control Release. 2016; 232: 51-61.

45. Alvarez-Erviti L, Seow Y, Yin H, Betts C, Lakhal S, Wood MJ. Delivery of siRNA to the mouse brain by systemic injection of targeted exosomes. Nat Biotechnol. 2011; 29(4): 341-5
46. Ding $\mathrm{Y}$, Cao $\mathrm{F}$, Sun $\mathrm{H}$, Wang $\mathrm{Y}$, Liu $\mathrm{S}$, Wu $\mathrm{Y}$, et al. Exosomes derived from human umbilical cord mesenchymal stromal cells deliver exogenous miR-145$5 p$ to inhibit pancreatic ductal adenocarcinoma progression. Cancer Lett. 2019; 442: 351-361.

47. Wang B, Yao K, Huuskes BM, Shen HH, Zhuang J, Godson C, et al. Mesenchymal Stem Cells Deliver Exogenous MicroRNA-let7c via Exosomes to Attenuate Renal Fibrosis. Mol Ther. 2016; 24(7): 1290-301.

48. Qiao L, Hu S, Huang K, Su T, Li Z, Vandergriff A, et al. Tumor cell-derived exosomes home to their cells of origin and can be used as Trojan horses to deliver cancer drugs. Theranostics. 2020; 10(8): 3474-3487.

49. Kim MS, Haney MJ, Zhao Y, Yuan D, Deygen I, Klyachko NL, et al. Engineering macrophage-derived exosomes for targeted paclitaxel delivery to pulmonary metastases: in vitro and in vivo evaluations. Nanomedicine. 2018; 14(1): 195-204.

50. Pascucci L, Coccè V, Bonomi A, Ami D, Ceccarelli P, Ciusani E, et al. Paclitaxel is incorporated by mesenchymal stromal cells and released in exosomes that inhibit in vitro tumor growth: a new approach for drug delivery. J Control Release. 2014; 192: 262-70.

51. Gilligan KE, Dwyer RM. Engineering Exosomes for Cancer Therapy. Int J Mol. Sci. 2017; 18(6): 1122

52. Wang X, Chen Y, Zhao Z, Meng Q, Yu Y, Sun J, et al. Engineered Exosomes with Ischemic Myocardium-Targeting Peptide for Targeted Therapy in Myocardial Infarction. J Am Heart Assoc. 2018; 7(15): e008737.

53. Wang J, Li W, Lu Z, Zhang L, Hu Y, Li Q, et al. The use of RGD-engineered exosomes for enhanced targeting ability and synergistic therapy toward angiogenesis. Nanoscale. 2017; 9(40): 15598-15605.

54. Tian Y, Li S, Song J, Ji T, Zhu M, Anderson GJ, et al. A doxorubicin delivery platform using engineered natural membrane vesicle exosomes for targeted tumor therapy. Biomaterials. 2014; 35(7): 2383-90.

55. Maléth J, Hegyi P. $\mathrm{Ca}^{2+}$ toxicity and mitochondrial damage in acute pancreatitis: translational overview. Philos. Trans. R. Soc. Lond., B, Biol. Sci. 2016; 371(1700):20150425.

56. Saluja A, Dudeja V, Dawra R, Sah RP. Early Intra-Acinar Events in Pathogenesis of Pancreatitis. Gastroenterology. 2019; 156(7): 1979-1993.

57. Antonucci L, Fagman JB, Kim JY, Todoric J, Gukovsky I, Mackey M, et al. Basal autophagy maintains pancreatic acinar cell homeostasis and protein. synthesis and prevents ER stress. Proc. Natl. Acad. Sci. U.S.A. 2015; 112(45): E6166-74.

58. Ron D, Walter P. Signal integration in the endoplasmic reticulum unfolded protein response. Nat. Rev. Mol. Cell Biol. 2007; 8(7): 519-29.

59. Hegyi P, Wilschanski M, Muallem S, Lukacs GL, Sahin-Tóth M, Uc A, et al. CFTR: a new horizon in the pathomechanism and treatment of pancreatitis. Rev Physiol Biochem. Pharmacol. 2016; 170:37-66.

60. Watanabe $\mathrm{T}$, Kudo $\mathrm{M}$, Strober $\mathrm{W}$. Immunopathogenesis of pancreatitis. Mucosal Immunol. 2017; 10(2): 283-298.

61. Hasan A, Moscoso DI, Kastrinos F. The role of genetics in pancreatitis. Gastrointest. Endosc. Clin. N. Am. 2018; 28(4): 587-603.

62. Khatua B, El-Kurdi B, Singh VP. Obesity and pancreatitis. Curr Opin Gastroenterol. 2017 ;33(5): 374-382.

63. Landahl P, Ansari D, Andersson R. Severe acute pancreatitis: gut barrier failure, systemic inflammatory response, acute lung injury, and the role of the mesenteric lymph. Surg Infect (Larchmt). 2015;16(6): 651-6.

64. Akbarshahi H, Rosendahl AH, Westergren-Thorsson G, Andersson R. Acute lung injury in acute pancreatitis--awaiting the big leap. Respir Med. 2012; 106(9):1199-210.

65. Zhou MT, Chen CS, Chen BC, Zhang OY, Andersson R. Acute lung injury and ARDS in acute pancreatitis: mechanisms and potential intervention. World J Gastroenterol. 2010; 16(17): 2094-9.

66. Vrolyk V, Singh B. Animal models to study the role of pulmonary intravascular macrophages in spontaneous and induced acute pancreatitis. Cell Tissue Res. 2020; 380(2): 207-222.

67. Elder AS, Saccone GT, Dixon DL. Lung injury in acute pancreatitis: mechanisms underlying augmented secondary injury. Pancreatology. 2012; 12(1): 49-56.

68. Browne GW, Pitchumoni CS. Pathophysiology of pulmonary complications of acute pancreatitis. World J. Gastroenterol. 2006; 12(44): 7087-96.

69. Chan BD, Wong WY, Lee MM, Cho WC, Yee BK, Kwan YW, et al. Exosomes in Inflammation and Inflammatory Disease. Proteomics. 2019; 19(8): e1800149.

70. Baghaei K, Tokhanbigli S, Asadzadeh H, Nmaki S, Reza Zali M, Hashemi SM. Exosomes as a novel cell-free therapeutic approach in gastrointestinal diseases. J Cell Physiol. 2019; 234(7): 9910-9926.

71. Tran TH, Mattheolabakis G, Aldawsari H, Amiji M. Exosomes as nanocarriers for immunotherapy of cancer and inflammatory diseases. Clin Immunol. 2015; 160(1): 46-58.

72. Harrell CR, Simovic Markovic B, Fellabaum C, Arsenijevic A, Djonov V, Arsenijevic N, et al. Therapeutic Potential of Mesenchymal Stem Cell-Derived Exosomes in the Treatment of Eye Diseases. Adv Exp Med Biol. 2018; 1089: 47-57.

73. Hough KP, Deshane JS. Exosomes in Allergic Airway Diseases. Curr Allergy Asthma Rep. 2019; 19(5): 26

74. Hough KP, Chanda D, Duncan SR, Thannickal VJ, Deshane JS. Exosomes in immunoregulation of chronic lung diseases. Allergy. 2017; 72(4): 534-544

75. Console $\mathrm{L}$, Scalise $\mathrm{M}$, Indiveri C. Exosomes in inflammation and role as biomarkers. Clin Chim Acta. 2019; 488: 165-171. 
76. Bonjoch L, Casas V, Carrascal M, Closa D. Involvement of exosomes in lung inflammation associated with experimental acute pancreatitis. J Pathol. 2016; 240(2): 235-45.

77. Jiménez-Alesanco A, Marcuello M, Pastor-Jiménez M, López-Puerto L, Bonjoch L, Gironella M, et al. Acute pancreatitis promotes the generation of two different exosome populations. Sci Rep. 2019; 9(1): 19887.

78. Bala S, Csak T, Saha B, Zatsiorsky J, Kodys K, Catalano D, et al. The proinflammatory effects of miR-155 promote liver fibrosis and alcohol-induced steatohepatitis. J. Hepatol. 2016 Jun;64(6):1378-87.

79. Bandiera S, Pfeffer S, Baumert TF, Zeisel MB. miR-122--a key factor and therapeutic target in liver disease. J. Hepatol. 2015; 62(2): 448-57.

80. Hsu SH, Wang B, Kota J, Yu J, Costinean S, Kutay H, et al. Essential metabolic, anti-inflammatory, and anti-tumorigenic functions of miR-122 in liver. J. Clin. Invest. 2012; 122(8): 2871-83.

81. Wang Z, Lieberman PM. The crosstalk of telomere dysfunction and inflammation through cell-free TERRA containing exosomes. RNA Biol. 2016; 13(8): 690-5.

82. Wang Z, Deng Z, Dahmane N, Tsai K, Wang P, Williams DR. Telomeric repeat-containing RNA (TERRA) constitutes a nucleoprotein component of extracellular inflammatory exosomes. Proc Natl Acad Sci U.S.A. 2015; 112(46): E6293-300.

83. Wu XB, Sun HY, Luo ZL, Cheng L, Duan XM, Ren JD. Plasma-derived exosomes contribute to pancreatitis-associated lung injury by triggering NLRP3-dependent pyroptosis in alveolar macrophages. Biochim Biophys Acta Mol Basis Dis. 2020; 1866(5): 165685.

84. Momen-Heravi F, Saha B, Kodys K, Catalano D, Satishchandran A, Szabo G. Increased number of circulating exosomes and their microRNA cargos are potential novel biomarkers in alcoholic hepatitis. J Transl Med. 2015; 13: 261.

85. Bala S, Petrasek J, Mundkur S, Catalano D, Levin I, Ward J, et al. Circulating microRNAs in exosomes indicate hepatocyte injury and inflammation in alcoholic, drug-induced, and inflammatory liver diseases. Hepatology. 2012; 56(5): 1946-57.

86. Chang W, Wang J. Exosomes and Their Noncoding RNA Cargo Are Emerging as New Modulators for Diabetes Mellitus. Cells. 2019; 8(8): 853.

87. Wang S, Wang JQ, Lv XW. Exosomal miRNAs as biomarkers in the diagnosis of liver disease. Biomark Med. 2017; 11(6): 491-501.

88. Harischandra DS, Ghaisas S, Rokad D, Zamanian M, Jin H, Anantharam V, Kimber M. Environmental neurotoxicant manganese regulates exosomemediated extracellular miRNAs in cell culture model of Parkinson's disease: Relevance to a-synuclein misfolding in metal neurotoxicity. Neurotoxicology. 2018; 64: 267-277.

89. Zhao Y, Wang H, Lu M, Qiao X, Sun B, Zhang W, et al. Pancreatic Acinar Cells Employ miRNAs as Mediators of Intercellular. Communication to Participate in the Regulation of Pancreatitis-Associated Macrophage Activation. Mediators Inflamm. 2018; 64: 267-277.

90. Cosenza S, Toupet K, Maumus M, Luz-Crawford P, Blanc-Brude O, Jorgensen $\mathrm{C}$, et al. Mesenchymal stem cells-derived exosomes are more immunosuppressive than. microparticles in inflammatory arthritis. Theranostics. 2018;8(5): 1399-1410.

91. Li J, Xue H, Li T, Chu X, Xin D, Xiong Y, et al. Exosomes derived from mesenchymal stem cells attenuate the progression of atherosclerosis in ApoE mice via miR-let7 mediated infiltration and polarization of M2 macrophage. Biochem Biophys Res Commun. 2019; 510(4): 565-572.

92. Rong X, Liu J, Yao X, Jiang T, Wang Y, Xie F. Human bone marrow mesenchymal stem cells-derived exosomes alleviate liver fibrosis through the Wnt/ $\beta$-catenin pathway. Stem Cell Res Ther. 2019; 10(1): 98.

93. Huang JH, Yin XM, Xu Y, Xu CC, Lin X, Ye FB, et al. Systemic Administration of Exosomes Released from Mesenchymal Stromal Cells Attenuates Apoptosis, Inflammation, and Promotes Angiogenesis after Spinal Cord Injury in Rats. J. Neurotrauma. 2017; 34(24): 3388-3396.

94. Jafarzadeh N, Safari Z, Pornour M, Amirizadeh N, Forouzandeh Moghadam $\mathrm{M}$, et al. Alteration of cellular and immune-related properties of bone marrow mesenchymal stem cells and macrophages by K562 chronic myeloid leukemia cell derived exosomes. J Cell Physiol. 2019; 234(4): 3697-3710.

95. Li Y, Jin D, Xie W, Wen L, Chen W, Xu J, et al. Mesenchymal Stem CellsDerived Exosomes: A Possible Therapeutic Strategy for Osteoporosis. Curr Stem Cell Res Ther. 2018; 13(5): 362-368

96. Liu J, Chen T, Lei P, Tang X, Huang P. Exosomes Released by Bone Marrow Mesenchymal Stem Cells Attenuate Lung Injury Induced by Intestinal Ischemia Reperfusion via the TLR4/NF-kB Pathway. Int J Med Sci. 2019; 16(9): 1238-1244.

97. Mao F, Wu $Y$, Tang $X$, Kang J, Zhang B, Yan $Y$, et al. Exosomes Derived from Human Umbilical Cord Mesenchymal Stem Cells Relieve Inflammatory Bowel Disease in Mice. Biomed Res Int. 2017; 2017: 5356760

98. Zhang S, Jiang L, Hu H, Wang H, Wang X, Jiang J, et al. Pretreatment of exosomes derived from hUCMSCs with TNF-a ameliorates acute liver failure by inhibiting the activation of NLRP3 in macrophage. Life Sci. 2020; 246: 117401.

99. Harrell CR, Simovic Markovic B, Fellabaum C, Arsenijevic A, Djonov V, Arsenijevic N, et al. Therapeutic Potential of Mesenchymal Stem Cell-Derived Exosomes in the Treatment of Eye Diseases. Adv Exp Med Biol. 2018; 1089: 47-57.

100. Ren J, Liu N, Sun N, Zhang K, Yu L. Mesenchymal Stem Cells and their Exosomes: Promising Therapeutics for Chronic Pain. Curr Stem Cell Res Ther. 2019; 14(8): 644-653.
101. Wang N, Ma J, Ren $Y$, Xiang S, Jia R. Secreted klotho from exosomes alleviates inflammation and apoptosis in acute pancreatitis. Am J Transl Res. 2019; 11(6): 3375-3383.

102. Coate KC, Hernandez G, Thorne CA, Sun S, Le TDV, Vale K, et al. FGF21 Is an Exocrine Pancreas Secretagogue. Cell Metab. 2017; 25(2): 472-480.

103. Singh VK, Yadav D, Garg PK. Diagnosis and Management of Chronic Pancreatitis: A Review. JAMA. 2019; 322(24): 2422-2434.

104. Kleeff J, Whitcomb DC, Shimosegawa T, Esposito I, Lerch MM, Gress T, et al. Chronic pancreatitis. Nat Rev Dis Primers. 2017; 3: 17060.

105. Majumder S, Chari ST. Chronic pancreatitis. Lancet. 2016; 387(10031): 1957-66.

106. Issa $Y$, Bruno MJ, Bakker OJ, et al. Treatment options for chronic pancreatitis. Nat Rev Gastroenterol Hepatol. 2014; 11(9): 556-64.

107. Kirkegård J, Mortensen FV, Cronin-Fenton D. Chronic Pancreatitis and Pancreatic. Cancer Risk: A Systematic Review and Meta-analysis. Am J Gastroenterol. 2017; 112(9): 1366-1372.

108. Apte MV, Pirola RC, Wilson JS. Mechanisms of alcoholic pancreatitis. J Gastroenterol Hepatol. 2010; 25(12): 1816-1826.

109. Lee AT, Xu Z, Pothula SP, Patel MB, Pirola RC, Wilson JS, Apte MV. Alcohol and cigarette smoke components activate human pancreatic stellate cells: implications for the progression of chronic pancreatitis. Alcohol Clin Exp Res. 2015; 39(11): 2123-2133.

110. Xue J, Sharma V, Hsieh MH, Chawla A, Murali R, Pandol SJ, et al. Alternatively activated macrophages promote pancreatic fibrosis in chronic pancreatitis. Nat Commun. 2015; 6: 7158 .

111. ApteM, PirolaR, WilsonJ. The fibrosis of chronic pancreatitis: new insights into the role of pancreatic stellate cells. Antioxid Redox Signal. 2011; 15(10): 2711-2722.

112. Ramakrishnan P, Loh WM, Gopinath SCB, Bonam SR, Fareez IM, Mac Guad R, et al. Selective phytochemicals targeting pancreatic stellate cells as new antifibrotic agents for chronic pancreatitis and pancreatic cancer. Acta Pharm Sin B. $2020 ; 10(3)$ : $399-413$

113. Mews P, Phillips P, Fahmy R, Korsten M, Pirola R, Wilson J, et al. Pancreatic stellate cells respond to inflammatory cytokines: potential role in chronic pancreatitis. Gut. 2002; 50(4): 535-41.

114. Bynigeri RR, Jakkampudi A, Jangala R, Subramanyam C, Sasikala M, Rao GV, et al. Pancreatic stellate cell: Pandora's box for pancreatic disease biology. World J Gastroenterol. 2017; 23(3): 382-405.

115. Li L, Wang G, Hu JS, Zhang GQ, Chen HZ, Yuan Y, et al. RB1CC1-enhanced autophagy facilitates PSCs activation and pancreatic fibrogenesis in chronic pancreatitis. Cell Death Dis. 2018; 9(10): 952.

116. Charrier A, Chen R, Chen L, Kemper S, Hattori T, Takigawa M, et al. Connective tissue growth factor (CCN2) and microRNA-21 are components of a positive feedback loop in pancreatic stellate cells (PSC) during chronic pancreatitis. J Cell Commun Signal. 2014; 8(2): 147-56.

117. Lai X, Wang M, McElyea SD, Sherman S, House M, Korc M. A microRNA signature in circulating exosomes is superior to exosomal glypican-1 levels for diagnosing pancreatic cancer. Cancer Lett. 2017; 393: 86-93.

118. Nakamura S, Sadakari Y, Ohtsuka T, Okayama T, Nakashima Y, Gotoh Y, et al. Pancreatic Juice Exosomal MicroRNAs as Biomarkers for Detection of Pancreatic Ductal Adenocarcinoma. Ann Surg Oncol. 2019; 26(7): 2104-2111.

119. Reese M, Flammang I, Yang Z, Dhayat SA. Potential of Exosomal microRNA$200 \mathrm{~b}$ as Liquid Biopsy Marker in Pancreatic Ductal Adenocarcinoma. Cancers (Basel). 2020; 12(1): 197

120. Pang Y, Wang C, Lu L, Wang C, Sun Z, Xiao R. Dual-SERS biosensor for one-step detection of microRNAs in exosome and residual plasma of blood samples for diagnosing pancreatic cancer. Biosens Bioelectron. 2019; 130: 204-213

121. Chen $\mathrm{D}, \mathrm{Wu} \mathrm{X}, \mathrm{Xia} \mathrm{M}, \mathrm{Wu} \mathrm{F}$, Ding J, Jiao $\mathrm{Y}$, et al. Upregulated exosomic miR-23b-3p plays regulatory roles in the progression of pancreatic cancer. Oncol Rep. 2017; 38(4): 2182-2188

122. Yang S, Che SP, Kurywchak P, Tavormina JL, Gansmo LB, Correa de Sampaio $\mathrm{P}$, et al. Detection of mutant KRAS and TP53 DNA in circulating exosomes from healthy individuals and patients with pancreatic cancer. Cancer Biol Ther. 2017; 18(3): 158-165.

123. Severino V, Dumonceau JM, Delhaye M, Moll S, Annessi-Ramseyer I, Robin X, et al. Extracellular Vesicles in Bile as Markers of Malignant Biliary Stenoses. Gastroenterology. 2017; 153(2): 495-504.

124. Watanabe $T$, Minaga $K$, Kamata $K$, et al. Mechanistic Insights into Autoimmune Pancreatitis and IgG4-Related Disease. Trends Immunol. 2018; 39(11): 874-889.

125. Kamisawa T, Takuma K, Egawa N, Tsuruta K, Sasaki T. Autoimmune pancreatitis and IgG4-related sclerosing disease. Nat Rev Gastroenterol Hepatol. 2010; 7(7): 401-9.

126. Nakamaru K, Tomiyama T, Kobayashi S, Ikemune M, Tsukuda S, Ito T, et al. Extracellular vesicles microRNA analysis in type 1 autoimmune pancreatitis: Increased expression of microRNA-21. Pancreatology. 2020; 20(3): 318-324.

127. Xu R, Rai A, Chen M, Suwakulsiri W, Greening DW, Simpson RJ, et al. Extracellular vesicles in cancer - implications for future improvements in cancer care. Nat Rev Clin Oncol. 2018; 15(10): 617-638.

128. Théry C, Witwer KW, Aikawa E, Alcaraz MJ, Anderson JD, Andriantsitohaina $\mathrm{R}$, et al. Minimal information for studies of extracellular vesicles 2018 (MISEV2018): a position statement of the International Society for Extracellular Vesicles and update of the MISEV2014 guidelines. J Extracell Vesicles. 2018; 7(1): 1535750. 
129. Kalluri R. The biology and function of exosomes in cancer. J Clin Invest. 2016; 126(4): 1208-15.

130. McAndrews KM, Kalluri R. Mechanisms associated with biogenesis of exosomes in cancer. Mol Cancer. 2019; 18(1): 52.

131. Gholizadeh S, Shehata Draz M, Zarghooni M, Sanati-Nezhad A, Ghavami S, Shafiee $\mathrm{H}$, et al. Microfluidic approaches for isolation, detection, and characterization of extracellular vesicles: Current status and future directions. Biosens Bioelectron. 2017; 91: 588-605.

132. Xu R, Greening DW, Zhu HJ, Takahashi N, Simpson RJ. Extracellular vesicle isolation and characterization: toward clinical application. J Clin Invest. 2016; 126(4): 1152-62.

133. Gandham S, Su X, Wood J, Nocera AL, Alli SC, Milane L, et al. Technologies and Standardization in Research on Extracellular Vesicles. Trends Biotechnol. 2020; 38(10):1066-1098.

134. Xu H, Jia S, Xu H. Potential therapeutic applications of exosomes in different autoimmune diseases. Clin Immunol. 2019; 205:116-124.

135. Garcia-Contreras M, Brooks RW, Boccuzzi L, et al. Exosomes as biomarkers and therapeutic tools for type 1 diabetes mellitus. Eur Rev Med Pharmacol Sci. 2017; 21(12):2940-2956.

136. Kimura K, Hohjoh H, Fukuoka M, et al. Circulating exosomes suppress the induction of regulatory $\mathrm{T}$ cells via let-7i in multiple sclerosis. Nat Commun. 2018;9(1):17 